\title{
O geoprocessamento como meio operacional e estratégico para defesa fronteiriça
}

\section{The Geoprocessing as strategic operational method to boundary defense}

Rev. Bras. Est. Def. v. 5, nº 1, jan./jun. 2018, p. 167-191 DOI: $10.26792 /$ RBED.v5n1.2018.75063

\section{SILMARA COSME CRAVO \\ PEDRO HENRIQUE FREIRE JANZANTTI}

\section{INTRODUÇÃO}

Definido por Rodrigues como "um conjunto de técnicas de coleta, exibição e tratamento de informações espacializadas" (Rodrigues 1990), o Geoprocessamento permite a integração de diversas variáveis, em diferentes temporalidades e formatos, para a análise da realidade complexa. Ele inclui diferentes Tecnologias da Informação Geográfica, entre elas: os Sistemas de Informações Geográficas (SIGs), as análises geoespaciais, a Cartografia Digital, a Cartografia Temática e o Sensoriamento Remoto.

Apesar de seu grande potencial, o Geoprocessamento é pouco aplicado em estudos de defesa fronteiriça. Encontrar dados geoespaciais sobre as nossas fronteiras, por exemplo, é um grande desafio. O Exército Brasileiro mantém uma plataforma, o Banco de Dados do Exército - BDGEx, que compõe a Infraestrutura Nacional de Dados Espaciais (INDE), e armazena diversos dados de caráter sistemático, como cartas topográficas em diferentes escalas e malhas viárias.

O Decreto $n^{\circ} 6.666$ de 27/11/2008 institui a INDE como um "conjunto integrado de tecnologias; políticas; mecanismos e procedimentos de coordenação e monitoramento; padrões e acordos, necessário para facilitar e ordenar a geração, o armazenamento, o acesso, o compartilhamento, a disseminação e o uso dos dados geoespaciais de origem federal, estadual, distrital e municipal” (Brasil 2008). Cumpre-se, assim, o atendimento à

Silmara Cosme Cravo - Doutoranda em Geografia na Faculdade de Filosofia, Letras e Ciências Humanas da Universidade de Sao Paulo.

Pedro Henrique Freire Janzantti - Estudante do Bacharel em Geografia da Faculdade de Filosofia, Letras e Ciências Humanas da Universidade de São Paulo (FFLCH/USP). 
necessidade de se ter um meio único de acesso a informações geográficas de forma interoperável.

Definida por Queiroz Filho e Giannotti (2012) como a integração e compartilhamento de informação no meio computacional, a interoperabilidade se caracteriza por dois principais processos interligados: a padronização dos seus componentes e, posteriormente, a sistematização de conceitos e termos.

Embora a INDE siga essas recomendações, seus dados são insuficientes para a disseminação do seu uso, uma vez que os produtos geoespaciais de que dispõe são pouco significativos na atualidade. A aceleração e o dinamismo contemporâneos demandam outros dados, para além de cartas sistemáticas como fonte de informação geográfica.

Para Harley (2009), nos dias de hoje, quanto mais complexa é a administração do Estado e quanto maiores são suas ambições territoriais e sociais, maior será a demanda por mapas. Por essas razões, argumentamos a favor da inclusão de dados geoespaciais, oriundos de diferentes Tecnologias da Informação Geográfica (TIGs), no BDGEx, o que poderia contribuir para subsidiar estudos de defesa fronteiriça.

Isto, no entanto, não é simples. Câmara et al. (2003) afirmam que um dos grandes desafios do Geoprocessamento é a representação do espaço geográfico em movimento (dinâmico). Pérez-Machado (2014) e Ferreira (2014) reconhecem uma defasagem na constituição epistemológica dessa área do conhecimento e acreditam ser essencial teorizar sobre o Geoprocessamento.

Neste artigo discutimos como o Geoprocessamento pode contribuir para os Estudos de Defesa da fronteira brasileira. Para tanto, apresentaremos os conceitos de Geopolítica e Território na Escola Geopolítica Brasileira para mostrar que o tema Defesa Fronteiriça é uma grande preocupação na atualidade. Por fim, explicaremos como as diferentes TIGs podem contribuir para operações de defesa fronteiriça e discutiremos o Geoprocessamento como meio analítico para resolução de problemas relacionados ao monitoramento fronteiriço.

\section{ALGUNS CONCEITOS FUNDANTES: GEOPOLÍTICA E TERRITÓRIO}

Ao se pensar a construção conceitual da geopolítica desde as suas origens, autores como Friedrich Ratzel, Rudolf Kjellén, Mackinder, Haushofer, Jacques Ancel e Aleksandr Dugin são fundamentais. Na América do Sul, da vizinha Argentina, podemos citar Raúl Rey Balmaceda e Federico Alberto Daus.

Para entendermos o conceito de geopolítica, há de se valer de uma abordagem com base na história do pensamento geográfico e também na Teoria 
Geral do Estado. Por um lado, há um ideário para justificar o advento da figura político-jurídica que é o Estado. Por outro lado, há a necessidade material do Estado de delimitar sua existência como entidade.

Antigamente, diferentes eram as razões de transformação dos limites territoriais. Por exemplo, um território poderia ser acrescido ao outro em função de ter havido um casamento que somasse as terras do reino da dinastia do marido àquelas da dinastia de sua esposa. Ou em função do resultado de guerra cujo prêmio oferecido ao vencedor era a posse de terras do inimigo. Hoje, a dinâmica das fronteiras é diferente e o território é tido como pressuposto básico do Estado.

O surgimento do Estado Moderno fez aprimorar conceitos e rigorosamente delimitá-los. São elementos do Estado: território, governo, povo e independência nas relações externas, sendo o primeiro, o mais geográfico. Portanto, em meados do século retrasado, o desenvolvimento da Geografia como ciência não poderia estar jamais desconectado da situação política vivida à época. Da mesma forma, acreditamos que a atual Geografia, que abriga o Geoprocessamento, também não pode estar distante do Estado e do conceito de território.

Embora as tecnologias não sejam suficientes para apreender o processo histórico jurídico de formação territorial, a reconstituição histórica desse movimento de consolidação de fronteiras (transformação geométrica de limites) poderia ser estruturada em um banco de dados geográfico. Imaginemos, então, a sobreposição de diferentes mapas, com a representação dos diferentes limites territoriais, e as possíveis operações analíticas para avaliação das mudanças de uso e ocupação do solo, dos limites administrativos e da toponímia.

Ao se percorrer diferentes autores da Escola Geopolítica Brasileira, percebemos uma convergência entre eles em relação à importância do território para a consolidação do Estado brasileiro. Um dos primeiros autores desse campo do conhecimento, Backheuser (1950), alicerçou a análise geográfica em três elementos: solo, clima e homem. Para ele, a Geopolítica é o ápice do conhecimento humano, e a consolidação territorial era pressuposto da ascensão da sociedade brasileira (Freitas 2004).

Mário Travassos analisou as vulnerabilidades e pontos fortes de cada país que compõe a América do Sul. Preconizou a necessidade de adoção de uma estratégia de interiorização política, econômica e demográfica por parte dos poderes públicos, sempre pensando na integração do conjunto continental (Freitas 2004).

Infelizmente, este é um intuito que até os dias de hoje não logrou alcançar êxito. Diferentes são os interesses que comandam a ocupação territorial. O Estado desde sempre ocupou papel central na definição dessas 
diretrizes; entretanto, fatores econômicos e demográficos são obstáculos à operacionalização desse projeto.

Golbery do Couto e Silva trabalhou os conceitos de Segurança Nacional e de Planejamento Governamental, aplicando-os quando foi Secretário de Segurança Nacional em 1937 e 1961 (Freitas 2004). Ele identificou ainda os limites e entraves que bloqueavam o Brasil a deslanchar rumo a uma posição de destaque.

Políticas militares e de infraestrutura foram desenvolvidas para impulsionar e alavancar polos de desenvolvimento no interior. Foi priorizada a construção de vias de transporte, aproveitamento de recursos, incentivo à navegação interior, criação de meios de escoamento de produtos, visando, enfim, a integração do território brasileiro.

Embora muitas vezes a geopolítica tenha uma conotação distorcida, reduzida ao totalitarismo, ao expansionismo ou à guerra (Costa 1996), essa área do conhecimento está igualmente interessada na consolidação do território como forma de reprodução da Nação através do desenvolvimento de seu povo.

Daí a razão de o território ser conceito central, e sua ocupação ser o primeiro passo para buscar o desenvolvimento integrado. Mais do que isso, a presença da população é entendida como uma das principais formas de garantir o território e protegê-lo. Sendo a fronteira algo vivo, em movimento, seu uso desempenha importância equivalente ao título de posse.

Conforme mostra a Figura 1, nos estudos da Geopolítica Brasileira e da Geopolítica em geral, não há categoria do conhecimento geográfico mais relevante do que a de território.

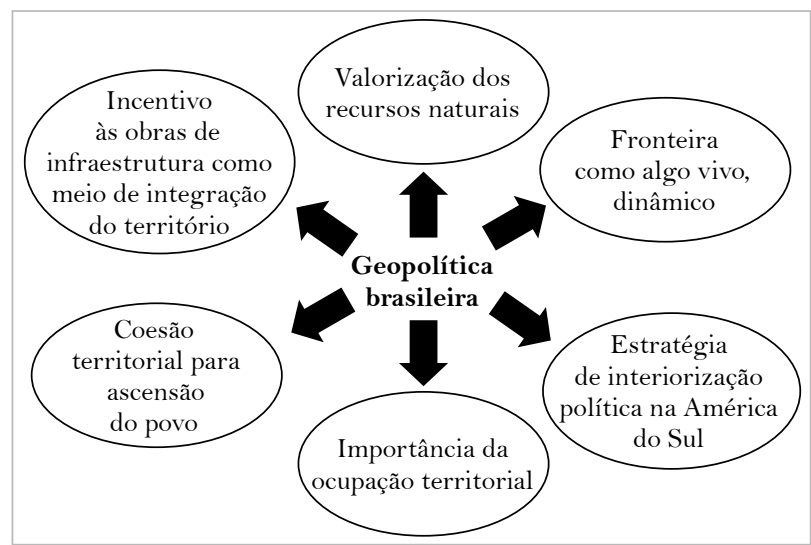

Figura 1 - Esquema que demonstra conceitos desdobrados da Geopolítica Brasileira.

Fonte: Elaboração dos autores. 
Se o território é um dos motivos de tensões internacionais, ele é ao mesmo tempo lugar de vivência do povo, por isso, a mais importante categoria de análise. Ao território, Ratzel (1988) atribuiu um valor, primeiro, de elemento fixador da família à localidade; segundo, por ser o germe de uma disposição política mais intrincada que a da família, da pátria ou da tribo.

Embora o geógrafo também possa falar em paisagem, área, região, habitat, etc. como modalidades possíveis (Martins 2014) para a abordagem do que é um Estado, a dimensão do território é mais precisa. Ela abarca a dimensão universal (do espaço) e a dimensão da singularidade, do caso específico de um Estado.

Não se pode perder de vista que o Estado é uma entidade política e coincidente com uma área de território (Moodie 1965) que está, justamente, circunscrito em uma área, o território. É aí que ele exerce sua soberania, impõe coercitivamente suas leis, oferece segurança ao seu povo. Nas relações exteriores, é reconhecido pelos Estados homólogos como pessoa jurídica soberana e independente em suas decisões.

O território é um dos elementos do Estado, sendo os outros: o povo, as leis, o governo e a independência nas relações externas (Dallari 2016). É atribuição do Estado prover tanto a segurança, quanto a defesa necessárias à sociedade. "A natureza vital e mais íntima do Estado, em última análise, é a sua sobrevivência sob ataque: sua defesa e segurança” (Figueiredo 2009, 23).

\section{MONITORAR PARA DEFENDER, O HISTÓRICO DE PROJETOS DE DEFESA FRONTEIRIÇA}

Com o aparecimento dos Estados Nacionais, surge a noção de territorialidade, impulsionada pelos tratados de paz de Westfália e o fim dos conflitos armados por disputas territoriais (Kissinger 2015). Essa noção define a proibição do uso da força pelo Estado para alterar seus limites (Zacher 2001), o que é referido aqui como respeito à soberania do Estado.

Entretanto, mesmo com o fim dos conflitos armados, sabemos que a demonstração de poder ainda existe e o território continua sendo central nessa disputa. Conforme a Estratégia Nacional de Defesa (Brasil 2012a), a expressão militar do país fundamenta-se na capacidade das Forças Armadas e no potencial dos recursos nacionais mobilizáveis.

O país deve dispor de meios para exercer vigilância, controle e defesa. A garantia da presença do Estado e a vivificação da faixa de fronteira, entretanto, são dificultadas pela baixa densidade demográfica e pelas longas distâncias. Por isso, é necessário desenvolver a dissuasão militar para fazer frente aos desafios, ao potencial de riscos e às ameaças do mundo atual (Costa 2012). 
Com sua dimensão continental e significativa extensão fronteiriça de quase 17.000 quilômetros, o Brasil faz fronteira com dez países da América do Sul, estando estrategicamente posicionado no Cone Sul, no Atlântico Sul. Não é à toa que Carlos de Meira Mattos (2002) e Therezinha de Castro (1997) enfatizam a projeção continental do Brasil e sua potência no cenário regional e mundial.

Com um território bastante extenso, um perfil continental e marítimo, equatorial, tropical e subtropical, o Brasil contém diversos recursos naturais e abarca uma heterogeneidade de usos e ocupações de solo. Assim, é fundamental monitorar e guardar sua faixa de fronteira, de forma a minimizar sua porosidade e evitar o trânsito ilegal de pessoas, mercadorias e informações. Uma extensão fronteiriça de tal monta requer um mecanismo de proteção e defesa de equivalente complexidade. A ocupação da fronteira infelizmente é estratégia praticamente inviável, por isso, é necessário definir pontos principais de fortificação.

Durante o Império, a política de defesa se organizava em torno das bacias hidrográficas. Logo, ela poderia ser considerada concentrada, restrita à Bacia do Prata e à Amazônia, foz oceânica sob controle nacional e faixa fronteiriça povoada por nativos (Marques 2001).

Os limites do território brasileiro que se tem hoje como 'mapa do Brasil' foram definitivamente delineados e estabilizados em 1907. O trabalho de consolidação de fronteiras teve seu apogeu no período do Império, Primeiro Reinado e Segundo Reinado (Vainfas 2008); o período imediatamente posterior, o da Primeira República, também foi de suma importância para definir os contornos do país.

Embora no passado o Brasil tivesse ambições expansionistas, os contenciosos territoriais do Brasil foram solucionados por negociações diplomáticas e arbitragens internacionais, que demarcaram as fronteiras com seus 10 vizinhos. Tanto assim que a Constituição da República Federativa do Brasil de 1988 orienta e caracteriza o perfil diplomático não beligerante do Estado brasileiro.

Em suma, não faz muito tempo que o Brasil consolidou suas fronteiras; seu território é significativo em dimensão, extensão fronteiriça e recursos; o histórico de defesa do país como um todo é recente, sendo anteriormente adstrito às bacias hidrográficas. $\mathrm{O}$ fato de o país não se envolver em guerra externa há algum tempo, aliado ao fato de ser um país que zela pela pacificidade, não podem levar à conclusão de que o Brasil jamais enfrentará problemas. Então, o Brasil não pode declinar a proteção de seus recursos.

Para os países poderosos, de acordo com Figueiredo (2009), a Defesa Nacional é inerente à própria vitalidade de seus interesses e objetivos no conjunto das nações. É tema que guarda relevância tanto sob o ponto de 
vista da introspecção, quanto sob o ponto de vista da extroversão, isto é, algo objetivo, exterior, coercitivo às suas próprias vontades.

A promulgação da Constituição da República Federativa do Brasil marca uma transição. Essa Constituição rompe com paradigmas anteriores e restaura uma nova ordem jurídica para o país. Foi isso o que ocorreu entre nós, na transição do regime militar para o regime democrático de direito, a partir do momento em que se devolveu ao povo brasileiro o sufrágio universal.

A Constituição da República marca uma mudança no projeto geopolítico de inspiração militar, de base ratzeliana, para outro projeto, o geopolítico civil, que só foi viável com a democratização do país (Costa 1992; Costa e Théry 2012). Com a sua promulgação, as iniciativas de proteção das fronteiras começam a assumir um caráter mais condizente com a de propagação ao longo do país, em contraposição àquela que se apoiava em uma política organizada em torno das bacias hidrográficas. A Tabela 1 resume esses avanços normativos que ocorreram após a democratização.

\section{Tabela 1}

Quadro-síntese do histórico de ações normativas para defesa fronteiriça

\begin{tabular}{|c|l|l|}
\hline Época & Projeto e Estratégias & Objetivo \\
\hline 1985 & Programa Calha Norte & $\begin{array}{l}\text { Promover a ocupação e o desenvolvimento ordenado } \\
\text { e sustentável da região amazônica. }\end{array}$ \\
\hline 2005 & $\begin{array}{l}\text { Política de Defesa } \\
\text { Nacional - PDN }\end{array}$ & $\begin{array}{l}\text { Estabelecer diretrizes para o preparo e o emprego } \\
\text { da capacitação nacional, com o envolvimento dos } \\
\text { setores militar e civil, em todas as esferas do Poder } \\
\text { Nacional. }\end{array}$ \\
\hline 2008 & $\begin{array}{l}\text { Estratégia Nacional de } \\
\text { Defesa - END }\end{array}$ & $\begin{array}{l}\text { Estabelecer diretrizes para a adequada preparação e } \\
\text { capacitação das Forças Armadas, de modo a garantir } \\
\text { a segurança do país, tanto em tempo de paz quanto } \\
\text { em situações de crise. Fortalecer três setores de } \\
\text { importância estratégica: espacial, cibernético e } \\
\text { nuclear. }\end{array}$ \\
\hline 2009 & $\begin{array}{l}\text { Estratégia Nacional de } \\
\text { Segurança Pública nas } \\
\text { Fronteiras - Enafron }\end{array}$ & $\begin{array}{l}\text { Intensificar o controle e a fiscalização nas fronteiras, } \\
\text { de forma a fortalecer a prevenção, o controle e a } \\
\text { repressão dos delitos transfronteiriços e outros } \\
\text { delitos praticados nas regiões da fronteira brasileira, } \\
\text { em parceria com estados e municípios. }\end{array}$ \\
\hline 2008 & $\begin{array}{l}\text { Sistema Integrado de } \\
\text { Monitoramento de } \\
\text { Fronteiras do Exército } \\
\text { Sisfron }\end{array}$ & $\begin{array}{l}\text { Fortalecer a presença e a capacidade } \\
\text { de monitoramento e de ação do Estado na faixa de } \\
\text { fronteira terrestre, potencializando a atuação dos } \\
\text { entes governamentais com responsabilidades sobre } \\
\text { a área. }\end{array}$ \\
\hline
\end{tabular}

Fonte: Brasil (2012a); Brasil (2012b); Enafron [s.d.]; Cossul e Jaeger (2016). 
O problema de defesa de fronteiras terrestres é assunto que demanda uma ação conjunta entre o Ministério da Defesa (criado em 10/06/1999 e que substituiu o Estado-Maior das Forças Armadas e os Ministérios Militares) e o Ministério das Relações Exteriores, órgão do Executivo responsável pelas Relações Internacionais e Política Externa.

São instrumentos orientadores da Defesa Nacional:

1)A Política de Defesa Nacional PDN, aprovada pelo Decreto $n^{\circ} 5.484$ de 30/06/2005, que foi atualizada em 2012 e passou a ser Política Nacional de Defesa PND (Brasil 2012c): fixa os objetivos da Defesa Nacional;

2)Estratégia Nacional de Defesa END de 2008, que foi revisada em 2012 (Brasil 2012a): operacionaliza os objetivos da Política Nacional de Defesa. Pauta-se por diretrizes, como por exemplo, a $2^{\text {a }}$ Diretriz da Estratégia Nacional de Defesa: organizar as Forças Armadas sob a égide do trinômio monitoramento/controle, mobilidade e presença; a $3^{\text {a }}$ Diretriz da Estratégia Nacional de Defesa: monitorar e controlar ar, terra e águas jurisdicionais; a $9^{\mathrm{a}}$ Diretriz da Estratégia Nacional de Defesa: adensar as Forças Armadas na fronteira; a $13^{\text {a }}$ Diretriz da Estratégia Nacional de Defesa: as tecnologias de comunicações devem ser encaradas como instrumentos potencializadores de iniciativas de defesa e combate.

A falta de vivificação em certos trechos da faixa fronteiriça é o que mais a deixa desprotegida. Por isso a importância desses projetos de integração territorial. Therezinha de Castro (1997), por exemplo, discute a centralização da ocupação brasileira e a necessidade de estratégias mais pragmáticas para fortalecer a posse territorial pela presença humana e promover a “integração pelo envolvimento".

Em específico, para a autora, o Brasil caracteriza-se como múltiplo vetor, isto é, possui potencial marítimo e continental. Para a valorização do Estado Brasileiro, o território é central e é essencial nos dedicarmos à obra integracionista para absorvermos nossas áreas geopolíticas neutras (Castro 1997).

"Se juridicamente a fronteira é uma linha, geograficamente e politicamente ela é uma zona, uma faixa de território limítrofe" (Gottmann 2007, 122). Nessa área, diversos são os conflitos. Entre eles, podemos apontar: as ocupações irregulares, a travessia de mercadorias, de armas, de munições, de drogas, de pessoas e de animais em condições ilícitas.

Os usos e ocupações dessa faixa fronteiriça caracterizam um risco à defesa nacional, pois a falta de regulamentação permite usos indevidos e 
que comprometem o equilíbrio no que diz respeito aos fluxos e infraestruturas. Essa área tem imprescindível valor político ao Brasil e requer normas específicas. Quando diz respeito às áreas de mata nativa, a depender do estatuto de zoneamento ecológico, a expansão de uso também pode se enquadrar em crime ambiental como desmatamento ilegal.

A circulação de mercadorias, por certo, muitas vezes caracteriza crimes como o contrabando e o descaminho, além do roubo de veículos e de suas respectivas cargas. A entrada descontrolada de armamento e munições, bem como o tráfico internacional de drogas, geram problemas sociais e econômicos nas grandes cidades. $\mathrm{O}$ trânsito de pessoas pela fronteira sem o controle de passaporte promove no interior do Brasil o abuso sexual, a prostituição, a exploração de trabalho infantil, de trabalho análogo ao de regime de escravidão, de trabalho precário, além da evasão de divisas. Quanto aos animais, podemos identificá-los como crimes ambientais contra a fauna brasileira.

A impunidade desses crimes configura uma afronta à soberania: primeiro, porque muitas vezes não há o registro e o processo legal capazes de atestar a existência do crime e, por consequência, a real frequência com a qual eles ocorrem. Segundo, porque sem o registro, sem o devido processo legal, não há sequer a possibilidade da emissão de auto de infração. Assim, a pena ao infrator não é aplicada, não há intimidação pela reincidência dos delitos, ou, em outras palavras, não é ação inibidora dos crimes, visto não haver controle sobre eles. Daí os delitos se repetirem diante da atuação inoperante dos órgãos que os deveriam reprimir.

A prerrogativa de o Estado aplicar a sanção penal ao autor do ilícito é um dos pressupostos da soberania e, neste caso, tem-se uma atenuação dessa função do Estado. Ora, a soberania foi elencada em primeiro lugar dentre todos os fundamentos da Constituição da República. Portanto, entendemos que afrontar a soberania é motivo de acirramento de tensões entre o Brasil e o país que deu causa ao ilícito.

\section{O GEOPROCESSAMENTO E O ESTADO BRASILEIRO}

O Geoprocessamento não é apenas um conglomerado de ferramentas, tampouco pode ser associado apenas à Geografia Humana ou Física. Ele consiste em formas de estruturar metodologias geográficas que propõem uma visão sistêmica, integrada e que tem como proposta enfrentar problemas concretos (Pérez-Machado 2014). A defesa fronteiriça é um desses problemas e requer um delineamento de variáveis e uma discussão interdisciplinar bem estruturada. 
No passado, antes do advento dos computadores, a produção de dados geoespaciais era de alta complexidade. No princípio, o Estado preocupou-se majoritariamente com a Cartografia Sistemática, os levantamentos topográficos e as definições de seus limites. Conforme demonstra Kantor (2007), a representação do continente nos mapas históricos constituía uma metáfora das possibilidades de apropriação do espaço real. O mapa, então, servia de instrumento jurídico no processo de demarcação das fronteiras.

A preocupação com o levantamento demográfico remonta ao ano de 1872, quando ocorreu o primeiro recenseamento nacional, o Recenseamento da População do Império Brasileiro (Oliveira 2003). Desde lá, o Estado, através de seus órgãos competentes (atualmente, o Instituto Brasileiro de Geografia e Estatística - IBGE), elaborou e produziu um conjunto de pesquisas bastante significativo no que diz respeito à oferta de informações sobre as diversas características demográficas e socioeconômicas da população brasileira (Oliveira e Simões 2002).

A evolução do IBGE como instituição pública, voltada tanto para a produção de estatísticas quanto para o conhecimento mais aprofundado do território brasileiro, pode ser considerada como um elemento do desenvolvimento da "autoconsciência coletiva" do país (Contel 2014). Produzir informação sobre o território e a população significa encarar com maior objetividade os problemas para conseguir delinear estratégias adequadas.

Já o levantamento dos recursos naturais é algo mais recente, visto a dimensão territorial brasileira e a necessidade de tecnologias mais complexas. É apenas entre 1970 e a primeira metade da década de 1980 que o projeto Radam Brasil é realizado e fornece um levantamento do território brasileiro quanto aos recursos naturais. De acordo com Ross (1985), essa aplicação pioneira de sensores radares aerotransportados permitiu um reconhecimento geral dos solos, da cobertura vegetal, da geologia, dos recursos hídricos e da geomorfologia.

A partir daí, temos duas fontes oficiais para a caracterização territorial socioambiental, pressuposto essencial para qualquer projeto de ordenamento territorial. Conforme Archela (2007) discute, o avanço de tecnologias ligadas ao Geoprocessamento trouxe também a necessidade de tratamento mais rigoroso aos dados coletados e à sua disseminação para a pesquisa, para o planejamento e para a população em geral.

Embora os mapas sejam protagonistas quando pensamos em Geoprocessamento, esse campo do conhecimento mostra-se mais do que simples veículo da informação visual. Trata-se de um meio analítico interdisciplinar com enfoque geográfico que diz respeito ao estudo da localização, da distribuição, da associação, da internalização e da evolução espacial (Pérez-Machado 2014). 
Diferentes tecnologias estão incluídas nesse campo do conhecimento chamado Geoprocessamento, entre elas o Sistema de Informação Geográfica, as análises geoespaciais, a Cartografia Digital e o Sensoriamento Remoto. Atualmente, com o acesso à rede mundial de computadores, a Internet, a difusão e o acesso a dados geoespaciais se faz de maneira corriqueira. Todavia, além de ter acesso aos dados, é necessário saber manipulá-los e analisá-los, de forma a garantir a qualidade dos resultados. Por fim, a divulgação e a tomada de decisão também são igualmente imprescindíveis.

Nesse sentido, são necessários sistemas complexos que abarquem todas essas funcionalidades do Geoprocessamento, desde a produção até as análises, primando pela qualidade e pelos padrões interoperacionais. A seguir são apresentadas as diferentes Tecnologias de Informação Geográfica e exemplos de aplicações para a Defesa Fronteiriça.

\section{1) Sistema de Informação Geográfica (SIGs)}

A partir de uma longa revisão de definições, Maguire (1991) define SIGs como sistemas integrados que consistem na conjunção do hardware, do software, do dado e do usuário, que buscam produzir mapas e bancos de dados geográficos. Para isso, grosso modo, essa ferramenta se estrutura basicamente na relação entre uma feição (geometria) georreferenciada e seus atributos.

A estrutura do banco de dados pode estar associada a feições em três formatos: pontos, linhas ou polígonos. Ao pensarmos na fronteira, podemos compreender os limites como linhas, os postos aduaneiros como pontos e os municípios que compõem a faixa fronteiriça como polígonos.

Para cada uma dessas formas, em SIG, podemos associar dados diversos. Os dados associados podem ser variáveis quantitativas, qualitativas, dicotômicas ou ordinais. No caso da questão fronteiriça, conforme Tabela 2, exemplificamos a ideia de como compor um banco de dado vetorial. $\mathrm{O}$ município, representado por um polígono, possui dados sociodemográficos; o posto aduaneiro, representado pelo ponto, possui dados tarifários; os limites, representados pela linha, possuem proprietários, toponímias ou classes de paisagem. 


\section{Tabela 2}

Tipos de feições que podem representar a materialidade contida nas faixas fronteiriças

\begin{tabular}{|l|l|l|}
\hline $\begin{array}{c}\text { Estrutura } \\
\text { vetorial }\end{array}$ & \multicolumn{1}{|c|}{ Significado } & \multicolumn{1}{|c|}{ Variáveis associadas } \\
\hline Polígono & Município, propriedades. & $\begin{array}{l}\text { População, economia, uso e ocupação do } \\
\text { solo. }\end{array}$ \\
\hline Ponto & $\begin{array}{l}\text { Postos aduaneiros, postos de } \\
\text { serviço. }\end{array}$ & $\begin{array}{l}\text { Produtos circulantes, arrecadação, } \\
\text { quantidade de funcionários, existência de } \\
\text { equipamentos de segurança. }\end{array}$ \\
\hline Linha & $\begin{array}{l}\text { Rede hidrográfica, estradas, } \\
\text { limites da propriedade. }\end{array}$ & $\begin{array}{l}\text { Nome, dimensão, responsável legal } \\
\text { pelo uso, nível de atenção necessária } \\
\text { (segurança). }\end{array}$ \\
\hline
\end{tabular}

Fonte: Elaboração dos autores.

Os bancos de dados geográficos têm também uma preocupação com a validade da geometria, isto é, com a existência de uma topologia correta. Topologia é uma propriedade matemática das geometrias que consiste nas relações de conectividade (intersecção), contiguidade (adjacência), continência (pertinência) e vizinhança, estabelecidas entre as feições. Apenas respeitando essas regras é que se tornam possíveis operações entre as diferentes camadas.

Dessa forma, é possível posicionar exatamente as feições de maneira amarrada, identificando as articulações e compreendendo as relações de tensões dentro de um contex to maior. $\mathrm{O}$ banco de dados geográfico infelizmente trabalha apenas dentro de uma métrica euclidiana, logo, apresenta os temas em função de distâncias métricas. Entretanto, no mundo contemporâneo, é impossível dissociar o par tempo-espaço. Por isso, um dos desafios dos bancos de dados é integrar diversas temporalidades.

Além do tempo-espaço, outras métricas são igualmente importantes para orientar análises. No caso dos estudos de defesa fronteiriça podemos pensar em métricas comparativas dos níveis de segurança, níveis de permeabilidade, níveis econômicos, características demográficas, entre outros. Calculados esses outros índices, as relações que em um primeiro momento eram apenas geométricas, de posicionamento, ganham outras dimensões. Daí ser possível tentar buscar outras relações entre as diferentes variáveis e a localidade de sua ocorrência.

Essa tecnologia permite buscar respostas para perguntas como: quais são os postos fronteiriços com maior fluxo de pessoas?; quais as regiões fronteiriças mais fortificadas?; quando há maior fluxo de mercadorias nos 
postos fronteiriços?; qual a infraestrutura existente nessa estrada fronteiriça? As possibilidades de perguntas são diversas. Entretanto, é imprescindível a constituição de um banco de dados geográfico, com atualização periódica, que inclua, entre outros, dados militares (mesmo que sejam sigilosos), econômicos, demográficos e referentes ao meio ambiente.

\section{2) A análise geoespacial}

Perguntas como as anteriores devem ser feitas através de operações de lógica espacial. Entretanto, as estratégias e as técnicas variam de acordo com os dados existentes. Em um primeiro momento, para fins de demonstração, podemos pensar em operações entre polígonos, um pouco mais simples.

Podemos explorar as possibilidades de união entre dois polígonos, podemos definir a área coincidente entre eles, ou mesmo a diferença, a depender do objetivo da análise. Não podemos nos esquecer que cada feição possui um conjunto de elementos associado em seu banco de dados. Cada operação baseia-se, assim, na tabela de atributos da feição; por consequência, ao gerar novas geometrias, devemos recalcular os dados em função desse novo limite. É importante pensar na distribuição dos fenômenos, isto é, a ocorrência dos fatos nem sempre se dá de forma homogênea. Assim, a natureza do fenômeno define seu nível de agregação.

Por isso é importante discutir a natureza dos dados geoespaciais. Conforme a Tabela 3 resume, existem três tipos de dados geoespaciais, e cada um tem suas respectivas possibilidades de operações de análises geoespaciais. O grande objetivo dessas operações é identificar padrões espaciais de forma a subsidiar inferências mais complexas.

Tabela 3

Tipos de dados geoespaciais

\begin{tabular}{|l|l|l|}
\hline \multicolumn{1}{|c|}{$\begin{array}{c}\text { Eventos ou padrões } \\
\text { pontuais }\end{array}$} & \multicolumn{1}{|c|}{ Superfícies contínuas } & $\begin{array}{c}\text { Áreas com contagens } \\
\text { ou taxas agregadas }\end{array}$ \\
\hline $\begin{array}{l}\text { Fenômenos expressos } \\
\text { através de ocorrências } \\
\text { identificadas como pontos } \\
\text { localizados no espaço, } \\
\text { denominados processos } \\
\text { pontuais }\end{array}$ & $\begin{array}{l}\text { Estimadas a partir de um } \\
\text { conjunto de amostras } \\
\text { de campo, que podem } \\
\text { estar regularmente ou } \\
\text { irregularmente distribuídas. } \\
\text { Geralmente, este tipo } \\
\text { de dado é resultante de } \\
\text { levantamento de recursos } \\
\text { naturais. }\end{array}$ & $\begin{array}{l}\text { Trata-se de dados } \\
\text { associados a levantamentos } \\
\text { populacionais, como censos, } \\
\text { e que originalmente se } \\
\text { referem a indivíduos } \\
\text { localizados em pontos } \\
\text { específicos do espaço. Por } \\
\text { razões de confidencialidade } \\
\text { esses dados são agregados } \\
\text { em unidades de análise. }\end{array}$ \\
\hline
\end{tabular}

Fonte: Câmara et al. (2002). 
Como Ferreira (2014) discute, é muito importante diferenciar informação geográfica de informação espacial. Uma informação geográfica é simplesmente aquela georreferenciada, associada a uma localidade, enquanto que a informação espacial se desdobra na exploração de características de dependência e influência entre os vizinhos (Ferreira 2014). Por essa razão é preciso considerar uma informação geográfica e explorá-la de forma a encontrar suas relações espaciais, como correlação, dependência, tendências, influência.

Concebida a estrutura do dado, o funcionamento de um SIG, e exploradas as devidas análise geoespaciais, podemos pensar na produção cartográfica. Com a plotagem em mapas e gráficos é possível buscar a representação da realidade, além de compreender a imagem como meio de comunicação.

\section{3) A Cartografia Digital e Temática}

A construção de mapas é apenas uma parte do Geoprocessamento, embora se imagine que seja seu produto final. Há também aqueles que supõem que os mapas são apenas uma ilustração, mas, conforme anteriormente demonstrado, a imagem tem alto potencial analítico. A realidade é mais do que limites normados. Assim, além das cartas topográficas, podemos e devemos produzir mapas temáticos, através da chamada Cartografia Temática.

De acordo com Archerla e Théry (2008), para representar os diversos temas é preciso recorrer a uma simbologia específica que, aplicada aos modos de implantação - pontual, linear ou zonal - aumentam a eficácia no fornecimento da informação. Bertin (2000), ao desenvolver a corrente da Neográfica, demonstrou que a construção do produto cartográfico deve ter como objetivo revelar informações dos dados e comunicá-las.

Conforme a Figura 2 mostra, para expressar relações de diferença, ordem e proporcionalidade entre dados de diferentes temáticas são utilizadas propriedades visuais. 


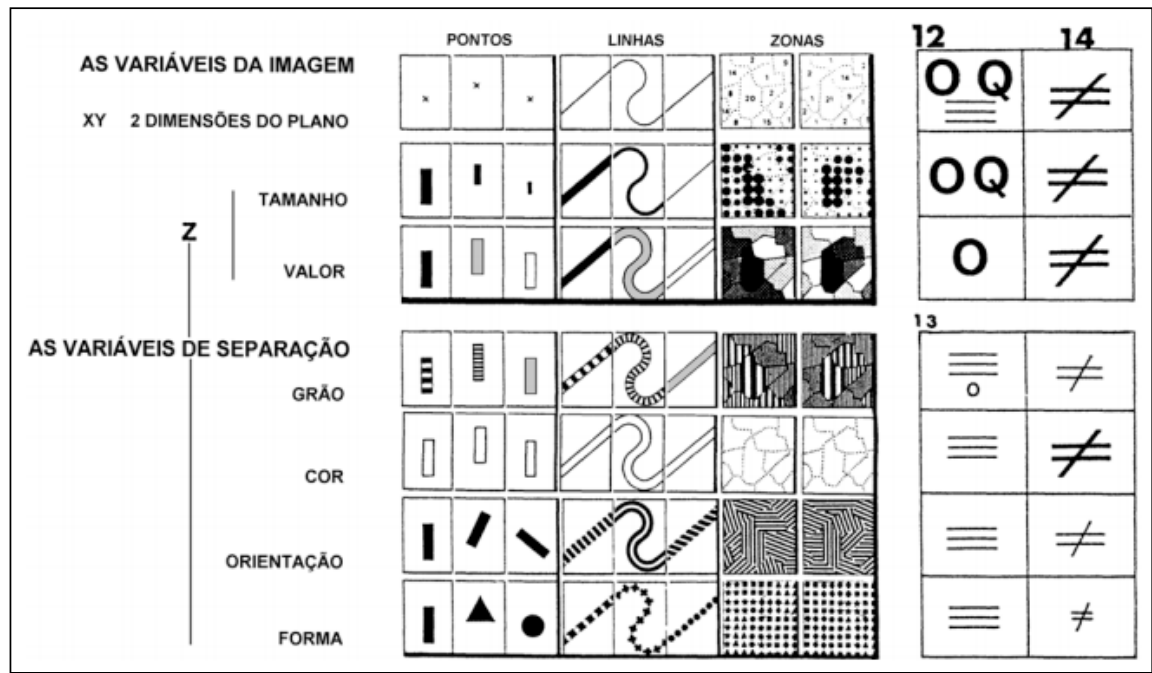

Figura 2 - Variáveis visuais de representação na Cartografia Temática e as diferentes relações entre os dados, $\mathrm{O}$ para ordem, $Q$ para proporção, $\neq$ para seletivo ou $\equiv$ para associativo. Fonte: Bertin (2000).

Uma das possibilidades de aplicação desse método é discutida por Queiroz Filho e Martinelli (2007), a Cartografia de Síntese. Opondo a Cartografia de Análise à de Síntese, os autores mostram que a primeira não é capaz por si só de sugerir as causalidades, enquanto que a segunda possui operações de análises geoespaciais embutidas e tem como produto novos resultados.

Outro desafio à superação da tradicional cartografia é a inserção do tempo nas representações, pois a dinâmica exige novas tecnologias e outros meios de apresentação dos mapas (Martinelli 2005).

Mesmo com essas problemáticas e uma ascensão de tecnologias mais focalizadas nas explorações em meio digital, ainda existem cartógrafos que tentam superar os limites da imagem tornando-a um meio de comunicação, retomando os princípios da Cartografia, como Théry (1997).

O mapa da Figura 3 demonstra a complexidade da realidade através da síntese de informações rodoviárias, hidrográficas, de planejamento territorial e ambiental, além de um compartimento geomorfológico, a Chapada dos Parecis. Além disso, as setas indicam movimente (origem e destino de fluxo). Esse mapa é um eficiente meio de discussão da relação entre o desmatamento da Amazônia e a construção da rede rodoviária, especialmente das estradas vicinais. 


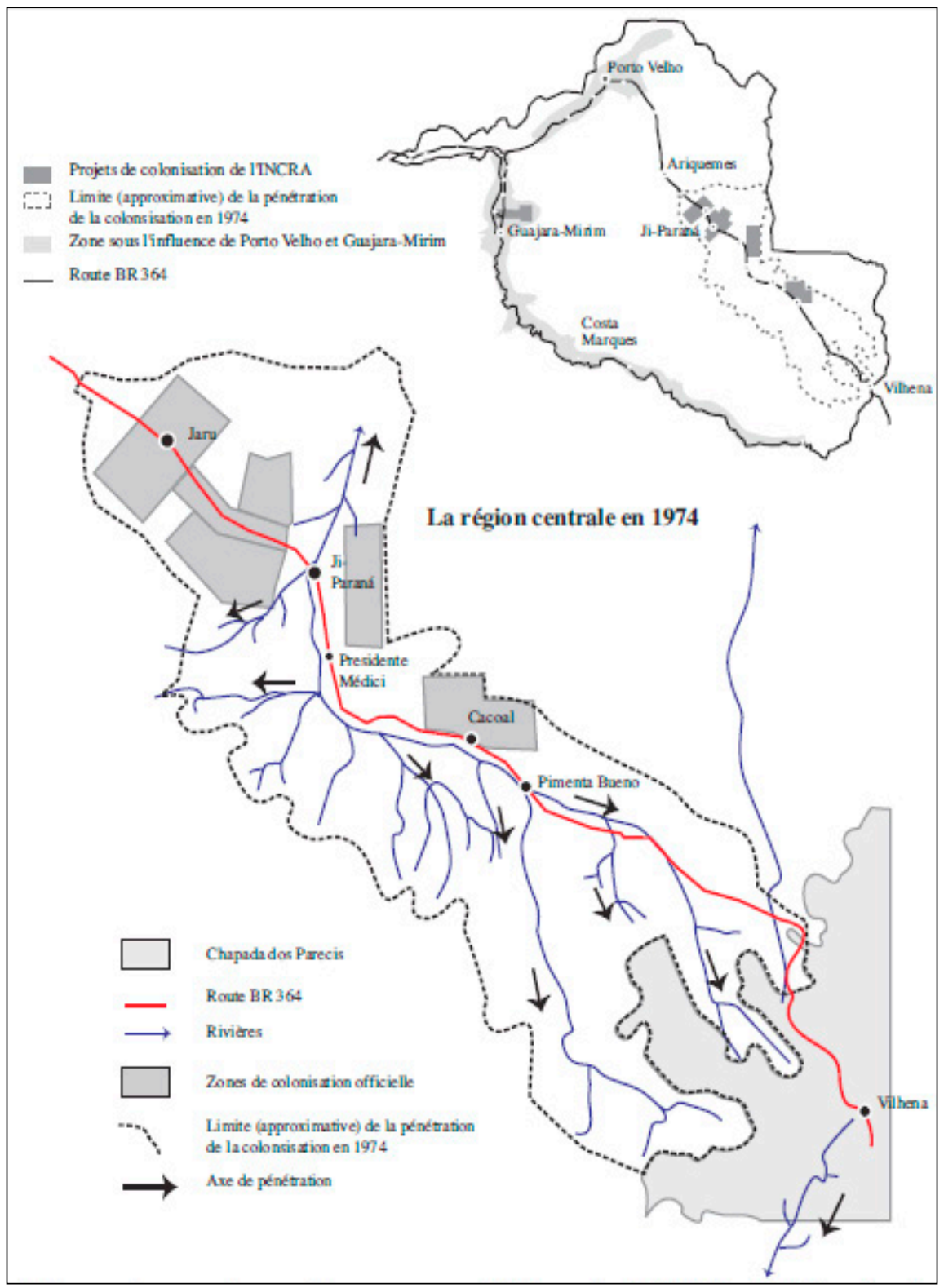

Figura 3 - Exemplo de cartografia de síntese sobre a temática do tipo de colonização e distribuição de terra adotada pelo Incra em meados de 1974.

Fonte: Théry (1997). 
Com esse exemplo, vemos como a Cartografia Temática, seguindo preceitos de simbologia como a de Bertin (2000)) e de Archela e Théry (2008), é um meio de comunicação e exige constante preocupação com a estética. Seu uso em larga escala com transmissão eficiente da mensagem requer definição de variáveis, cuidado com as cores e com o layout.

São inúmeras as perguntas que poderiam ser respondidas através de mapas temáticos, de grandezas quantitativas, qualitativas ou ordenadas. Entre elas, poderíamos pensar na evasão de divisas representada por setas, como fluxos; pensar na localização dos municípios com maior densidade demográfica e seu Produto Interno Bruto através de sobreposição de temáticas; ou mesmo, qual tipo de equipamento de defesa existe em cada ponto da fronteira, usando variáveis seletivas e ordenadas, hierarquizando assim o grau de proteção de cada trecho.

\section{4) Sensoriamento Remoto}

O Sensoriamento Remoto, por sua vez, pode contribuir para o monitoramento de áreas distantes e de difícil acesso. Essa tecnologia utiliza o princípio físico da radiação eletromagnética para apreensão de informação. Sua característica principal é a capacidade de obter informação à distância. Através de sensores alocados em satélites orbitais, balões, aviões e veículos aéreos não tripulados (VANTs), capta sinais emitidos pelos objetos presentes na superfície terrestre para mapeá-la.

O produto dessa técnica é um raster, isto é, uma imagem, composta por uma matriz (linha x coluna) de pixel (em português, elemento da imagem). Cada pixel tem um valor específico proveniente de sua refletância ou equivalente nível de cinza (dentro de uma escala que depende de uma característica específica do sensor).

Os sensores possuem diversas especificações técnicas, a saber: resolução temporal, espacial, radiométrica e espectral. A primeira diz respeito ao tempo de revisita de um sensor para gerar uma nova imagem da mesma área; a segunda representa o tamanho mínimo que o objeto precisa ter para ser discriminado na imagem; a terceira é a relação com a quantidade de níveis de cinza (em bit) que representará a refletância de cada alvo; e a última é a medida da largura das faixas espectrais e da sensibilidade do sistema do sensor. Para os nossos propósitos, consideramos as duas primeiras as mais importantes, resolução temporal e espacial.

Observemos a combinação de uma imagem de satélite estéreo com o modelo digital de superfície (extraído de uma imagem de radar). Essa articulação de dados de duas fontes diferentes permite a visualização tridimensional de um projeto de uma base militar (Figura 4). Essa construção 
simula o planejamento de campos de batalha, entre outras atividades estratégicas militares.

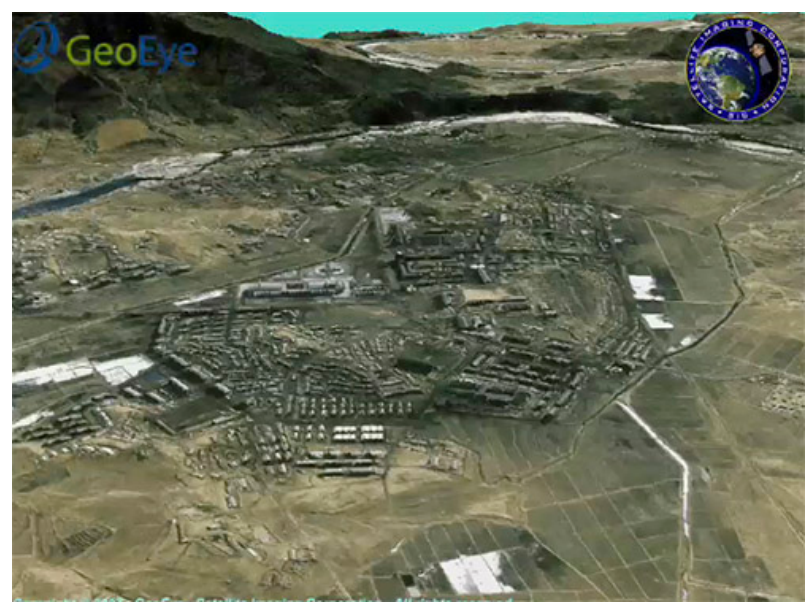

Figura 4: Imagem Stereo Ikonos de resolução espacial de $1 \mathrm{~m}$ e modelo digital de superfície de $2 \mathrm{~m}$.

Fonte: DigitalGlobe and 3D Flythrough by Satellite Imaging Corp [s.d.].

Este exemplo mostra que a resolução espacial deve ser definida em função da aplicação do estudo. Por se tratar de uma captura para implementar uma base militar, não é necessário um sensor que apresente intervalo curto de revisita para captura de outra imagem. Apenas uma imagem é suficiente para prover o contexto da área.

No caso das fronteiras, é importante especificar qual o objeto que se quer investigar e qual a vulnerabilidade que pode ser enfrentada. Pensemos, por exemplo, no monitoramento do fluxo de pessoas para inibir o trânsito ilegal. Sensores orbitais atualmente disponíveis não permitem capturar vídeo, isto é, movimento. Entretanto, existem sensores específicos para essa demanda, que possuem um tipo de processamento específico. Outra questão importante é a alta resolução espacial necessária para se identificar uma pessoa em uma imagem.

Por outro lado, para o controle de uso e ocupação do solo, para o qual o tempo de revisita não precisa ser tão curto e a resolução espacial não precisa ser tão alta, os sensores orbitais disponíveis hoje têm grande potencial. Igualmente interessante seria a identificação de recursos naturais existentes nas faixas fronteiriças, como as barreiras naturais e as altera- 
ções da paisagem. O espaço antrópico (ambiente construído) também pode ser monitorado para que se possam avaliar temporalmente as condições das infraestruturas que buscam a integração do território.

\section{CONCLUSÃO}

Como foi dito, o território é a dimensão geográfica que identifica o Estado. O Brasil, desde há algum tempo, não passa por problemas que afetam diretamente seu território. Inserido na América do Sul, está distante de diferentes conflitos que assolam o mundo atual: terrorismo, extrema intolerância religiosa e política, fragmentação de seu território, etc. Vivemos em uma região razoavelmente pacífica e que goza de uma estabilidade no que se refere ao cenário internacional. Atualmente é um país que prima pela resolução pacífica de conflitos, sendo uma nação não beligerante.

Entretanto, seria ingênuo não deixar o Estado brasileiro pronto à resistência caso um dia seja necessário perseguir seus interesses geopolíticos. Seguindo a Estratégia Nacional de Defesa, é dever do Brasil conhecer seus recursos e seu território, bem como protegê-los.

A Cartografia serve então para mapear o território e representar a consolidação do poder. No passado, esse conhecimento era obtido por intermédio de cartas militares; com o passar do tempo, a carta sobre o meio analógico foi substituída pela Cartografia Digital e outros recursos surgiram para representar e analisar a realidade, cada vez mais complexa.

Procuramos mostrar algumas das inovações disponíveis para a análise das informações territoriais com o uso do Geoprocessamento, permitindo a sistematização de dados, a produção de informação, a análise dos dados, as modelagens. O Geoprocessamento pode preencher um vazio de informação territorial e orientar a tomada de decisão.

Os atributos da fronteira são diversos e vão desde a largura da faixa de fronteira (estabelecida por lei) até valores da Geografia Física e Humana, como relevo, vegetação, população, disponibilidade de trabalho e infraestrutura com seus pontos fixos instalados (aduana, postos diversos).

Atualmente contamos com as informações do BDGEx, porém, o potencial do Geoprocessamento e de suas Tecnologias da Informação Geográfica são pouco explorados nos seus dados geoespaciais. Trata-se de um recurso rico de representação e de análise da territorialidade que requer dados de qualidade e de diferentes fontes.

Importante advertir que, para a construção de uma INDE mais robusta e análises geoespaciais mais complexas, é preciso contar com uma equipe qualificada de profissionais que domine o Geoprocessamento. Como Lacoste (2014) adverte: os mapas, para quem não aprendeu a lê-los e uti- 
lizá-los, não têm nenhum sentido, assim como as páginas escritas também não têm para aqueles que não aprenderam a ler. Daí a importância de se assegurar a formação de profissionais que entendam a natureza desses dados e da problemática da defesa fronteiriça. Os dados geoespaciais são uma representação da realidade, e a defesa fronteiriça é mais complexa que a simples articulação de variáveis em um sistema.

Certamente a tecnologia não vai resolver todos os problemas da vulnerabilidade fronteiriça brasileira, pois as fronteiras também apresentam uma dimensão não material das relações de poder que a fizeram nascer (Raffestin 1980). Entretanto, o Geoprocessamento tem grande potencial para subsidiar as decisões quando associado ao conhecimento militar estratégico.

Posto isso, esperamos que presente artigo levante discussões interdisciplinares no que tange ao estudo da defesa e ao Geoprocessamento, impulsionando trabalhos empíricos futuros para cobrir essa agenda de pesquisa de suma importância.

\section{BIBLIOGRAFIA}

Archela, Rosely Sampaio. 2007. Evolução histórica da Cartografia no Brasil Instituições, formação profissional e técnicas cartográficas. Revista Brasileira de Cartografia, 3 (59).

Archela, Roseli Sampaio e Hervé Théry. 2008. Orientação metodológica para construção e leitura de mapas temáticos. Confins: Revista Franco-brasileira de Geografia, $3(1)$.

Backheuser, Everardo. 1950. Leis Geopolíticas da Evolução dos Estados. Boletim Geográfico. 8 (88). Rio de Janeiro: IBGE.

Bertin, Jacques. 2000. A Neográfica. Tradução: Jayme Antonio Cardoso. Curitiba: Universidade Federal do Paraná.

Brasil. 1988. Constituição da República Federativa do Brasil. Brasília, DF: Senado, 1988.

Brasil. 2005. Decreto $n^{0}$ 5.484, de 30 de junho de 2005. Aprova a Política de Defesa Nacional e dá outras providências. Decreto do Executivo, Brasília, DF, 30 jun. 2005. http://www.planalto.gov.br/ccivil-03/_Ato2004-2006/2005/Decreto/ D5484.htm.

Brasil. 2008. Decreto $n^{\circ} 6.666$ de 27 de novembro de 2008. Institui, no âmbito do Poder Executivo federal, a Infra-Estrutura Nacional de Dados Espaciais- INDE, e 
dá outras providências. Decreto do Executivo, Brasília, DF, 27 nov. 2008. http:// www.planalto.gov.br/ccivil_03/_ato2007-2010/2008/decreto/d6666.htm.

Brasil. 2012a. Política Nacional de Defesa. Estratégia Nacional de Defesa. Brasília: Ministério da Defesa.

Brasil. 2012b. Livro Branco de Defesa Nacional. Brasília: Ministério da Defesa.

Brasil. 2012c. Política Nacional de Defesa. http://www.defesa.gov.br/arquivos/2012/mes07/pnd.pdf.

Brasil. [s.d.] Folheto Sisfron. Brasília: EPEX Escritório de Projetos do Exército, Exército Brasileiro: Braço Forte - Mão Amiga.

Câmara, Gilberto, Antônio Miguel Vieira Monteiro, Suzana Druck Fucks e Marília Sá Carvalho. 2002. Análise espacial e geoprocessamento. In: Fucks, Suzana Druck; Câmara, Gilberto; Carvalho, Marília Sá; Monteiro, Antônio Miguel Vieira, organizadores. Análise espacial de dados geográficos. Brasília: EMBRAPA Cerrados.

Câmara, Gilberto; Monteiro, Antônio Miguel Vieira; Medeiros, José Simeão de. 2003. Representações computacionais do espaço: fundamentos epistemológicos da ciência da geoinformação. Geografia, Rio Claro, 28 (1): 83-96.

Castro, Therezinha de. 1997. América do Sul: vocação geopolítica. Rio de Janeiro: Escola Superior de Guerra.

Contel, Fabio Betioli. 2014. As divisões regionais do IBGE no século XX (1942, 1970 e 1990). Terra Brasilis (Nova Série), 3: 1-17.

Cossul, Naiane Inez e Bruna Coelho Jaeger. 2016. O Papel da Infraestrutura no Combate aos Ilícitos Transfronteiriços na América do Sul. Revista Brasileira de Estudos de Defesa, 3 (1).

Costa, Wanderley Messias da. 1992. Geografia Política e Geopolítica: discursos sobre o território e o poder. São Paulo: HUCITEC: Editora da Universidade de São Paulo.

Costa, Wanderley Messias da. 1996. O estado e as políticas territoriais no Brasil. 5. ed. São Paulo: Contexto.

Costa, Wanderley Messias da. 2012. Projeção do Brasil no Atlântico Sul: geopolítica e estratégia. Revista USP, 95: 9-22. 
Costa, Wanderley Messias da e Hervé Théry. 2012. Quatre-vingts ans de géopolitique au Brésil: de la géographie militaire à une pensée stratégique nationale. Hérodote, 3: 253-276.

Dallari, Dalmo de Abreu. 2016. Elementos de Teoria Geral do Estado. 33. ed. São Paulo: Saraiva.

ENAFRON. [s.d.] http://www2.camara.leg.br/atividade-legislativa/comissoes/ comissoes-permanentes/credn/audiencias-publicas/2011/acompanhar-e-esclarecer-as-acoes-e-dificuldades-encontradas-para-prover-a-devida-protecao-asfronteiras-brasileiras-1/apresentacao-enafron.

Ferreira, Marco César. 2014. Iniciação à análise geoespacial: teoria, técnicas e exemplos para geoprocessamento. São Paulo: Unesp.

Figueiredo, Eurico de Lima. 2009. "A produção do conhecimento: Poder, Política e Defesa Nacional”. In: Rocha, Marcio (Org.). Política - Ciência e Tecnologia - Defesa Nacional/Universidade da Força Aérea. Rio de Janeiro: UNIFA, nov.: 11-25.

Freitas, Jorge Manoel da Costa. 2004. A Escola Geopolítica Brasileira. Rio de Janeiro: Biblioteca do Exército Editora.

Gottmann, Jean. 2007. La politique des États et leur géographie. Trad. Katia Bienvenu. Paris: Éditions du CTHS.

Guichonnet, Paul; Raffestin, Claude. 1974. Géographie des frontières. Paris: PUF.

Harley, Brian. 2009. "Mapas, saber e poder". Confins: Revista Franco-brasileira de Geografia, 5.

Kantor, Íris. 2007. "Usos diplomáticos da ilha-Brasil. Polêmicas cartográficas e historiográficas”. Varia História, 23 (37): 70-80.

Kissinger, Henry. 2015. Ordem Mundial. Trad. Cláudio Figueiredo. 1. ed. Rio de Janeiro: Objetiva.

Lacoste, Yves. 2014. La géographie, ça sert, d'abord, à faire la guerre. Édition augmentée. Paris: La Découverte.

Maguire, David J. 1991. "An overview and definition of GIS". Geographical Information Systems: Principles and applications, 1: 9-20.

Marques, Adriana Aparecida. 2001. Concepções de defesa nacional no Brasil: 1950 -1996. 154 f. Dissertação (Mestrado em Ciência Política) - Instituto de Filosofia e Ciências Humanas, Universidade de Campinas, São Paulo. 
Martinelli, Marcello. 2005. "Cartografia dinâmica: espaço e tempo nos mapas”. GEOUSP - Espaço e Tempo (Online), 18: 53-66.

Martins, Élvio Rodrigues. 2014. "As dimensões do geográfico: diálogo com Armando Corrêa da Silva”. GEOUSP - Espaço e Tempo (Online), São Paulo, 18 (1): 40-54.

Mattos, Carlos de Meira. 2002. Geopolítica e Modernidade: geopolítica brasileira. Rio de Janeiro: Biblioteca do Exército Editora.

Moodie, A. E. 1965. Geografia e Política. Trad. Christiano Monteiro Oiticica. Rio de Janeiro: Zahar Editores.

Oliveira, Jane Souto. 2003. "Brasil mostra a tua cara": imagens da população brasileira nos censos demográficos de 1872 a 2000. Rio de Janeiro, RJ (Brasil): ENCE/ IBGE. 69 p. (Texto para discussão, n. 6)

Oliveira, Luiz Antonio Pinto de e Celso Cardoso da Silva Simões. 2013. "O IBGE e as pesquisas populacionais”. Revista Brasileira de Estudos de População, 22 (2): 291-302.

Pérez-Machado, Reinaldo Paul. 2014. "Os novos enfoques da geografia como apoio das tecnologias da informação geográfica”. Revista do Departamento de Geografia, v. Especial Cartogeo, 203-241.

Queiroz Filho, Alfredo Pereira e Mariana Abrantes Giannotti. 2012. "Mapas na Web”. Revista do Departamento de Geografia. 171-189.

Queiroz Filho, Alfredo Pereira e Marcello Martinelli. 2007. "Cartografia de análise e de síntese na geografia”. Boletim Paulista de Geografia, 87 : 7-44.

Raffestin, Claude. 1980. Pour une géographie du pouvoir. Paris: Techniques.

Ratzel, Friedrich. 1988. "El território, la sociedad y el Estado". In: Cantero, Nicolás Ortega; Jiménez, Julio Muñoz; Mendonza, Josefina Gómez. El pensamiento geográfico: estudio interpretativo y antología de textos (de Humboldt a las tendencias radicales). 2 ed. (corregida y ampliada). Madrid: Alianza Editorial. 193-203.

Rodrigues, Marcos. 1990. "Introdução ao Geoprocessamento”. In: Simpósio Brasileiro de Geoprocessamento, 1, São Paulo. Anais... São Paulo: POLI/USP. 1-26.

Ross, Jurandyr Luciano Sanches. 1985. "Relevo brasileiro: uma nova proposta de classificação”. Revista do Departamento de Geografia, São Paulo, 4. 
Satellite Imaging Corp. [s.d.] “Homeland Security”. https://www.satimagingcorp. com/applications/defense-mapping/homeland-security/.

Théry, Hervé. 1997. "Routes et déboisement en Amazonie brésilienne, Rondônia 1974-1996”. Mappe Monde, Maison de la géographie, 97 (3): 35-40.

Vainfas, Ronaldo (Org.). 2008. Dicionário do Brasil imperial. Rio de Janeiro: Objetiva. 301-302.

Zacher, Mark W. 2001. "The territorial integrity norm: International boundaries and the use of force". International Organization, 55(2): 215-250. 


\section{RESUMO}

A vulnerabilidade da fronteira brasileira representa insegurança nacional. Neste artigo discutiremos como diferentes Tecnologias da Informação Geográfica do Geoprocessamento podem contribuir para estudos sobre defesa da fronteira brasileira. Para tanto, apresentamos o background teórico que justifica a aplicação do Geoprocessamento no monitoramento fronteiriço.

Palavras-Chave: Fronteira; Geoprocessamento; Segurança Nacional; Território.

\section{ABSTRACT}

Border vulnerability means national insecurity. This paper discusses how Geographic Information Technologies of Geoprocessing might support Brazilian border defense research. It was considered the theoretical background that explains the application of these technologies in border monitoring.

Key-words: Border; Geoprocessing; National Security; Territory.

Recebido em 02/05/2018. Aceito para publicação em 29/10/2018. 